\title{
KAUFMANN, Thomas, Martin Luther
}

\section{Philippe Büttgen}

\section{OpenEdition \\ Journals}

Édition électronique

URL : http://journals.openedition.org/ifha/744

DOI : 10.4000/ifha.744

ISSN : 2198-8943

Éditeur

IFRA - Institut franco-allemand (sciences historiques et sociales)

\section{Référence électronique}

Philippe Büttgen, «KAUFMANN, Thomas, Martin Luther », Revue de I'IFHA [En ligne], Date de recension, mis en ligne le 01 janvier 2006, consulté le 22 septembre 2020. URL : http://journals.openedition.org/ ifha/744 ; DOI : https://doi.org/10.4000/ifha.744

Ce document a été généré automatiquement le 22 septembre 2020.

(CIFHA 


\title{
KAUFMANN, Thomas, Martin Luther
}

\author{
Philippe Büttgen
}

1 En 128 pages, format de rigueur, le nouveau Luther de la collection «Wissen » réussit à relier les informations essentielles à une approche personnelle du Réformateur. Th.K. part des " deux natures » de Luther, ou comment le moine saxon Martinus Luder, homme de prière et de lecture, devint « Luther », Eleutherius, l'« homme libre » qui au début de la querelle des Indulgences transforma son nom pour se changer en « star des médias » (p. 8), infatigable promoteur de sa cause et de lui-même, personnage public producteur d'espace public - «l'Allemand des temps anciens sur lequel nous savons le plus de choses » (p. 13). Luther, ses vies, ses œuvres : celle, monastique, professorale, biblique de l'homme d'Église qu'il ne cessa jamais d'être après avoir créé la sienne ; celle, politique (le Prince, l'Empereur), polémique (Rome, les Paysans, les « Schwärmer »), commerciale (l'imprimerie), de l'homme public. Cette tension permanente, qui est aussi celle de deux mondes sociaux, explique selon Th.K. la polarité que l'historiographie - Lucien Febvre, en France, y a sa part - n'a cessé de subir, plutôt que de penser, entre le jeune Luther, inventeur et progressiste, et le vieux, orthodoxe et conservateur, comme elle détermine le développement ultérieur du mouvement de Réformation, de la contestation anabaptiste au gel progressif des positions confessionnelles à partir de 1530. Dans le cas de Luther, la contradiction se résout pourtant dans ce que Th.K. appelle une " existence théologique ", dont la description contient des formulations particulièrement frappées : on retiendra la caractérisation du projet luthérien comme " interprétation expérimentale de l'Écriture » et " autointerprétation de l'homme dans l'horizon de la Parole de Dieu » (p. 63) doublée, sur le versant politique, d'une «théologie de l'ordre enracinée dans la Bible» (p. 83). Des « deux natures " de Luther à son " existence théologique ", citation barthienne, l'imprégnation théologique du propos rend sensible à un problème : comment faire l'histoire d'un homme qui ramène lui-même toute son évolution à celle d'un « rapport à Dieu » et semble se dérober à toute autre formule d'explication, psychologique, sociale, économique ? Comment, autrement dit, historiciser ce " mobile »-là (p. 27), sans le réduire à autre chose, parce que ce n'est pas possible, et sans s'en remettre à la Providence, parce que ce n'est pas le lieu ? La question est celle de toute biographie de Luther, c'est celle aussi d'un certain rapport allemand à la Vie de grand homme, conçue 
comme reconstitution d'un dialogue intime avec une puissance divine ou démonique. Th.K. suit ce modèle, sans doute fixé par Luther lui-même, mais pare à ses dangers en laissant son sujet parler de lui. Les titres et qualificatifs que Luther s'est choisis (" Docteur de l'Écriture sainte ", "Ecclésiaste ", «Prophète des Allemands ", « Réformateur »...) livrent le point de départ du récit et de l'analyse, avec pour résultat que tout ce qu'il faut savoir sur Luther - et tout y est : le couvent d'Erfurt, les Indulgences, la traduction de la Bible, les Paysans, les femmes, la haine antisémite et antimusulmane - lui est rendu, c'est-à-dire renvoyé à la responsabilité d'un théologien qui fut habité à la fois de l'écho de la Parole et du souci de lui-même. C'est sans doute pourquoi ce petit livre élégant, distancié sans être distant, sur les « deux natures » de Luther, méritera aussi d'être lu deux fois.

Philippe BÜTTGEN (Centre National de la Recherche Scientifique/ MHFA) 